\title{
Juvenile Osteoporosis
}

\author{
P. LAPATSANIS, A. KAVADIAS, and K. VRETOS \\ From the Paediatric and Orthopaedic Departments, Aghia Sophia Children's Hospital, Athens, Greece
}

Lapatsanis, P., Kavadias, A., and Vretos, K. (1971). Archives of Disease in Childhood, 46, 66. Juvenile osteoporosis. Two cases of idiopathic juvenile osteoporosis are described; one with the mild form of the disease, and the other with the severe form. The common findings were pain in the feet or in the lumbar spine, with a negative calcium balance. Phosphorus balance was negative only in the child with the severe form of the disease.

Idiopathic juvenile osteoporosis (Dent and Friedman, 1965; Dent and Watson, 1966; Fanconi et al., 1966; Cloutier et al., 1967; Dent, 1969) affects children between 8 and 14, and is characterized by pain in the feet, spine, or elsewhere, susceptibility to fractures, generalized osteoporosis including long bones, and usually negative calcium balance. Complete recovery is the rule. We report here two additional cases.

\section{Methods}

Blood collections were made at about 9 a.m. and the serum separated immediately. The method of King and Armstrong (1934) was used for estimating serum alkaline phosphatase; of MacIntyre (1961) for calcium; of Fiske and Subbarow (1925) for phosphorus; and of Sky-Peck (1964) for magnesium. 24-hour collections of urine were considered acceptable if the value for the creatinine excretion did not differ by more than $20 \%$ from its mean 24-hour value. Faeces were marked with carmine red at the beginning and end of each 3-day study period. Chromium sesquioxide $(200 \mathrm{mg} \pm$ $2 \mathrm{mg}$ ) was administered before the three main meals of the day; the child used a preweighed tin to receive faeces. The method of Whitby and Lang (1960) was used for estimating chromium sesquioxide in the stools.

The children were on a mixed diet during the studies, with food cooked using distilled water. These specially prepared meals were given both before and during the studies. The dishes with fixed amounts of food were sent to the ward. The child had the first dish, and the second dish was put in a weighing tin for food. Though for the children the cook made meals with the dishes preferred by these patients, they often did not eat the full amount of food, and the residue of food after each meal was put in another weighing tin. At the end of each day we removed the residue from the food tin after all meals, thus measuring exactly the residual amount of food in quantity which the child did not eat,

Received 4 June 1970. and the type of food not consumed was also taken into consideration.

A food amount with the same weight as the daily food that was being taken by the child in each day was made homogeneous. From this food a sample equal to one-fifth of the daily food amount was kept every day during the 3 days of study period, and then a mixture of the 3 one-fifth samples was prepared. Two separated samples $(50 \mathrm{~g}$ each) were taken from the above mixture for the estimation of $\mathrm{Ca}, \mathrm{Mg}$, and $\mathrm{P}$. A sample was considered as correct if the difference between the two food samples ( $50 \mathrm{~g}$ each) for calcium and phosphorus was less than $3 \mathrm{mg} / 100 \mathrm{~g}$ and for magnesium was less than $1 \mathrm{mg} / 100 \mathrm{~g}$. Two samples of faeces $(50 \mathrm{~g} \mathrm{each})$ were received from the homogeneous collection of the stools. Similarly, a sample of the faeces was considered as correct if the difference between the two stool samples (50 g each) was less than $3 \mathrm{mg} / 100 \mathrm{~g}$ for $\mathrm{Ca}$ and $\mathrm{P}$ and less than $1 \mathrm{mg}$ for $\mathrm{Mg}$.

\section{Case Reports}

Case 1. This girl of 8 complained of increasing pain in the left ankle and toes from the beginning of January 1967. The first attack of pain was noticed when she was hit by a stone thrown by another girl at school. In March 1967 she was admitted to a hospital; no swelling or signs of active infection were found. Hb $11.5 \mathrm{~g} /$ $100 \mathrm{ml}$; WBC normal; antistreptolysin 250, 625, and 833 Todd units (on different dates); ESR 6, 15, and $44 \mathrm{~mm}$ in 1 hour; rheumatoid factor negative. Penicillin, aspirin, and prednisone ( $30 \mathrm{mg}$ daily for 4 weeks) were given without effect.

In June 1967 she was admitted to this hospital. She then had difficulty in walking and in climbing stairs. The feet were not swollen, but were painful on passive and active movements. The following investigations were normal: $\mathrm{Hb}, \mathrm{WBC}$ and differential count, ESR, electrolytes, plasma urea, CRP, lupus cells, ASO, SGPT, SGOT, serum aldolase, serum total protein, electrophoretic strip, blood sugar, blood creatine and creatinine, bone-marrow, urinary 17-steroids, and 17-ketogenic steroids, urine creatine and creatinine 


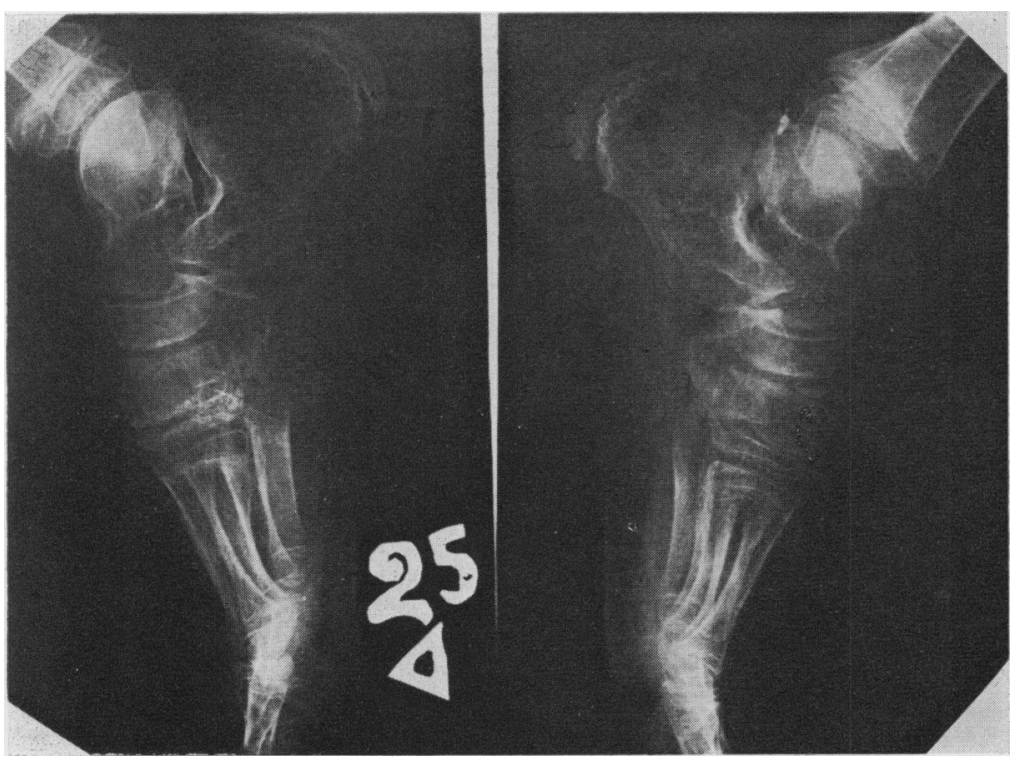

FIG. 1.-Case 1. X-ray of the feet showing marked osteoporosis.

output, and fat balance. Fig. 1 shows the radiological appearance of osteoporosis in the bones of the feet.

In June 1967 (Fig. 2) a 3-day balance study showed that the patient had a negative calcium balance and a positive balance for phoshorus and magnesium. Serum calcium, phosphorus, magnesium, and alkaline phosphatase were within normal limits throughout the period of follow-up.

She was encouraged to walk, and improved gradually. In August 1967 she was shown to be in positive calcium balance (calcium supplement was given as her diet was low in calcium).

From the time of discharge in September 1967 until April 1968 she was well and attended school, playing games normally. Her height was $130 \mathrm{~cm}$ (75th centile). In April 1968 the patient still had a positive calcium, phosphorus, and magnesium balance. $X$-rays of long bones (Fig. 3) now showed no signs of osteoporosis. Since that time she has remained well.

Case 2. This boy was born in 1956 of unrelated parents. He was well until August 1967 when he complained of increasing pain in the lumbar spine. He gradually became unsteady on walking. $X$-ray of spine (November 1967, Fig. 4) showed marked osteoporosis. On admission (December 1967) to hospital

FIG. 2.-Case 1. The diagram shows the treatment and biochemical investigations. The patient was in negative calcium balance in June 1967, and then throughout the period of follow-up she has remained in positive calcium, phosphorus, and magnesium balance and this has corresponded to the radiological improvement observed in her bones.
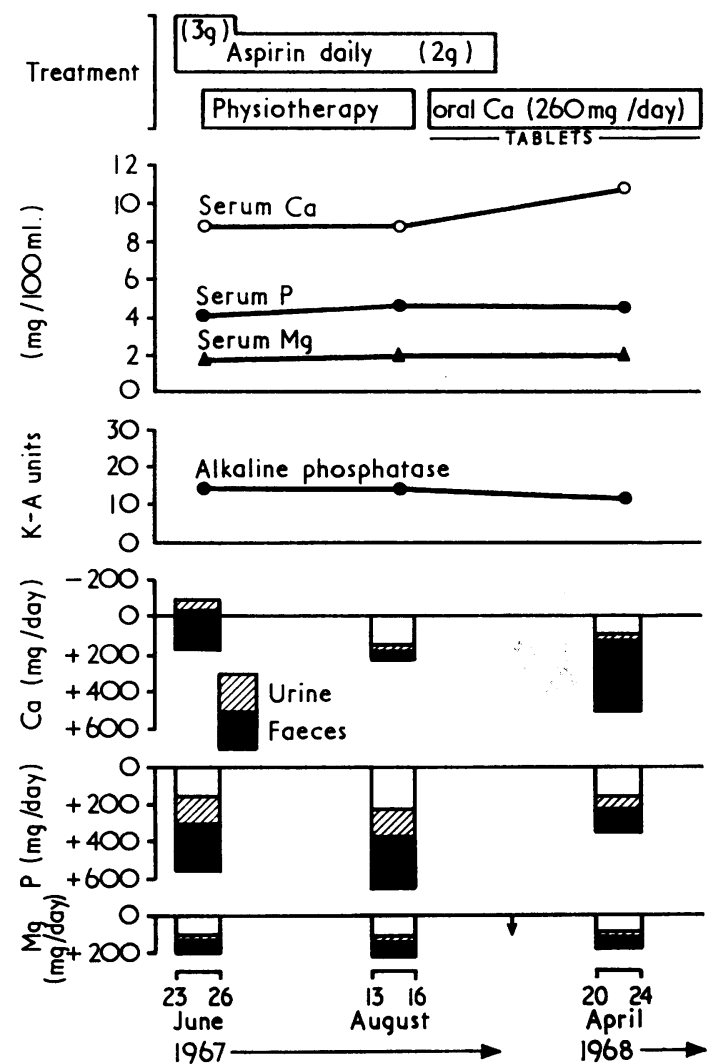

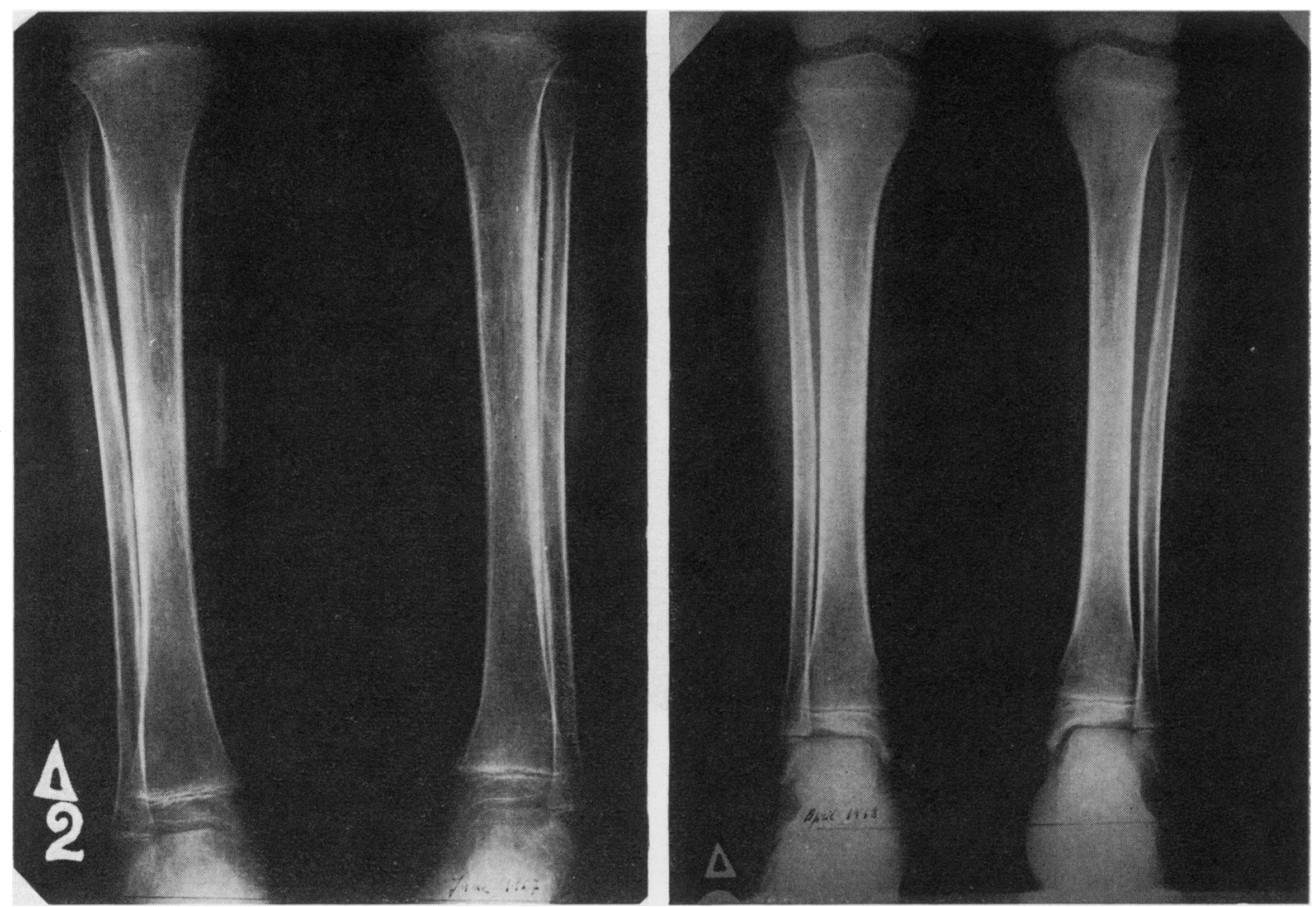

FIG. 3.-Case 1. X-rays of the tibiae (a) in June 1967, showing rarefaction of the long bones with a thin cortex of the tibiae; (b) in April 1968 showing no osteoporosis.

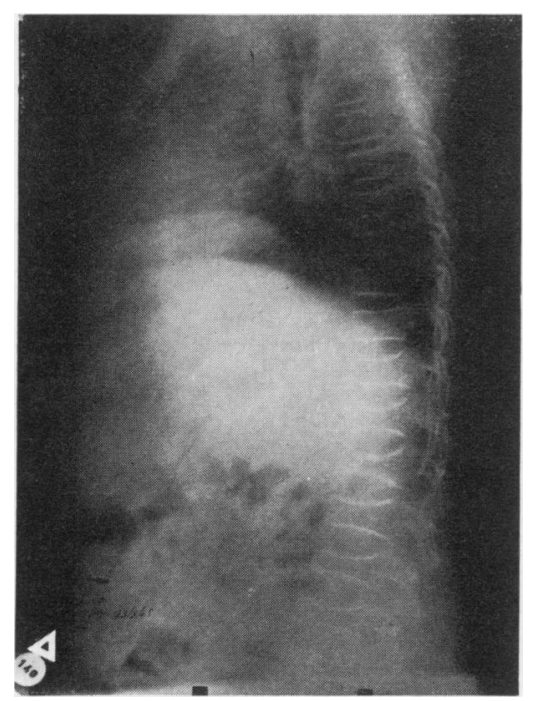

FIG. 4.-Case 2. All vertebral bodies show a biconcave appearance with expansion of the intervertebral spaces. he was unable to walk, but the cause for this was not obvious on clinical examination. The following investigations were normal: $\mathrm{Hb}, \mathrm{WBC}$ and differential count, ESR, electrolytes, plasma urea, total protein, electrophoretic strip, rheumatoid factor, CRP, intravenous pyelogram, urinary 17-ketosteroids and 17ketogenic steroids, and fat balance.

In January 1968 he was found to be in negative calcium, phosphorus, and magnesium balance (Fig. 5).

Because his diet was low in calcium, extra calcium and vitamin $\mathrm{D}$ supplement were given. During the first period, the fall in serum calcium need not be considered significant, as it is within normal limits (Fig. 5). He was unable to walk even with crutches, and in March and July 1968 he still had a negative calcium and phosphorus balance. There was a gradual clinical improvement from September 1968. In December 1968 he had a positive calcium balance for the first time, and in September 1969 he had a positive phosphorus balance for the first time. With regard to the calcium, phosphorus, and magnesium data shown in Fig. 5, though a technical error may have affected the first three recordings (January, March, and July 1968), they seem certainly to indicate a negative calcium and phosphorus balance. The other three balance studies (December 1968, and May and September 1969) were very carefully double-checked. A bone specimen of the 

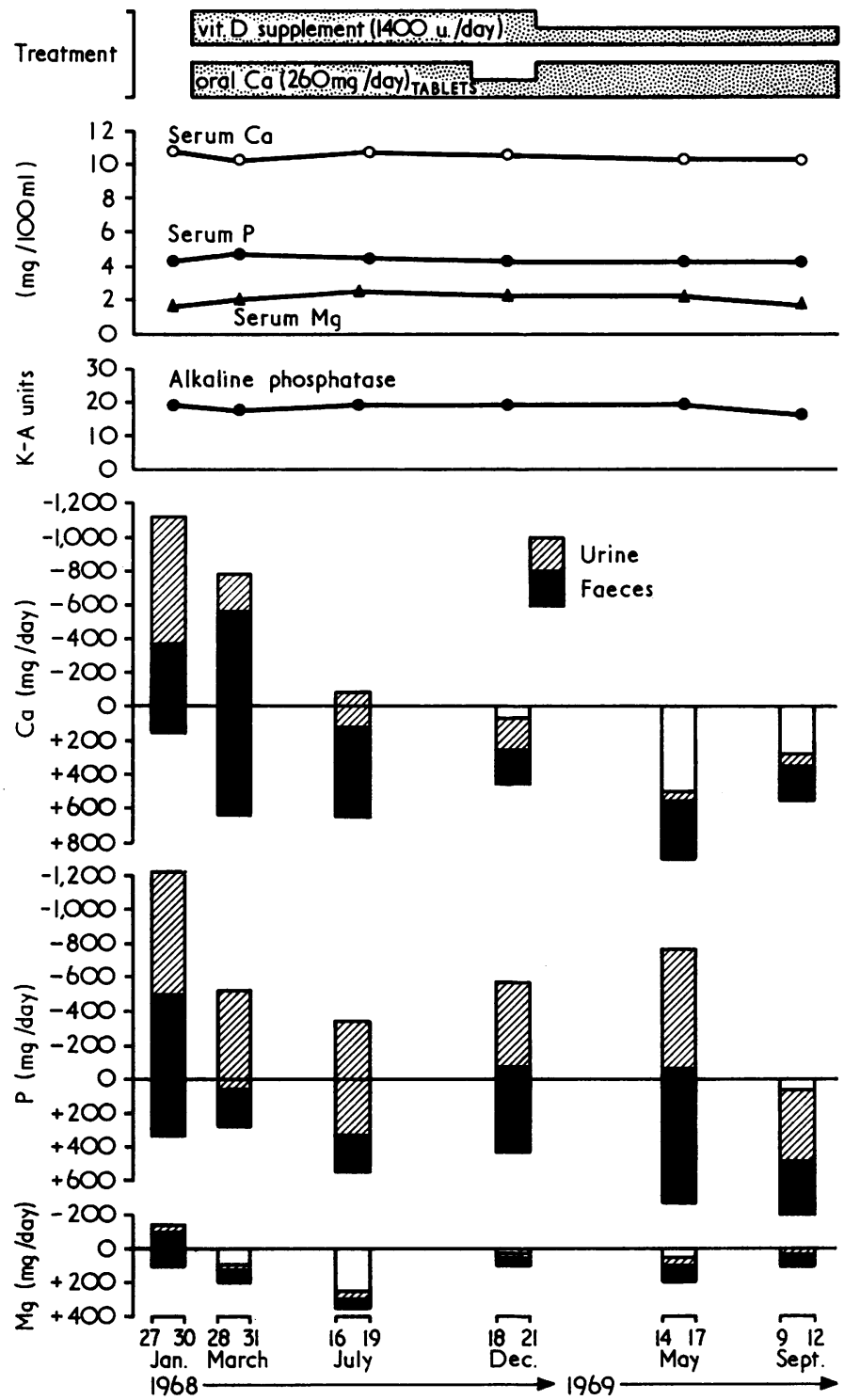

FIG. 5.-Case 2. This diagram shows the treatment and biochemical investigations. The patient was in negative calcium and phosphorus balance throughout the period from January 1968 until July 1968. Calcium balance became positive in December 1968 and phosphorus balance in September 1969 while magnesium balance was positive from March 1968 and throughout the period of follow-up.

left iliac crest was obtained on 18 May 1969 and showed a thick periosteum and a thick bone cortex, with the thin lamellar osseous tissue that is typical of osteoporosis. The bone-marrow was normal.

In December 1968 he started to walk with crutches, and since May 1969 has been able to walk a few steps without crutches, and to climb stairs by himself with the aid of crutches. At that time radiological improvement was observed. Since then he has continued to have a positive calcium balance, and to show steady clinical improvement.

From April 1969 he has been walking for several hours daily using crutches. His height in May 1969 was $145 \mathrm{~cm}$ (just below the 10th centile). 


\section{Discussion}

The main clinical, radiological, and metabolic findings of our two patients are shown in the Table. Pain in the joints or spine was the main clinical feature of the disease. Clinical symptoms persisted for three months after the start of treatment in the first child, and for 11 months in the second.

Pain after minimal trauma can be the first manifestation of the disease (Dent and Friedman, 1965) and was so in both patients. The height of Case 1 was on the 75th centile, and in Case 2 just below the 10th centile. Dwarfism has been reported in patients with juvenile osteoporosis as the result of fractures, though such patients grew normally after osteoporosis improved (Fanconi et al., 1966; Cloutier et al., 1967; and Dent, 1968). Osteoporosis of the vertebral bodies, long bones, and bones of the feet and hands was marked, and persisted even after clinical improvement was evident. Dent $(1968,1969)$ pointed out that in the severe type of juvenile osteoporosis there is a porotic metaphysial area in all growing parts of the skeleton;
TABLE

Clinical, radiological, and metabolic findings in Cases 1 and 2

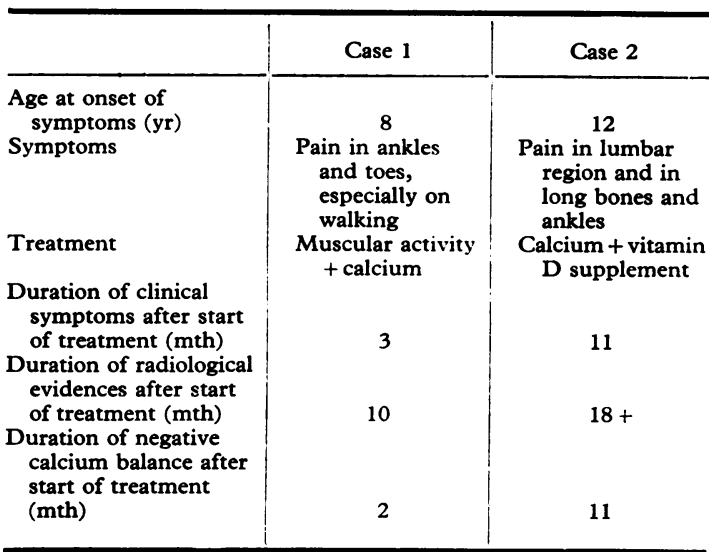

this part of the bone may fracture with minimal trauma, as in our Case 2 (Fig. 6). Oral calcium

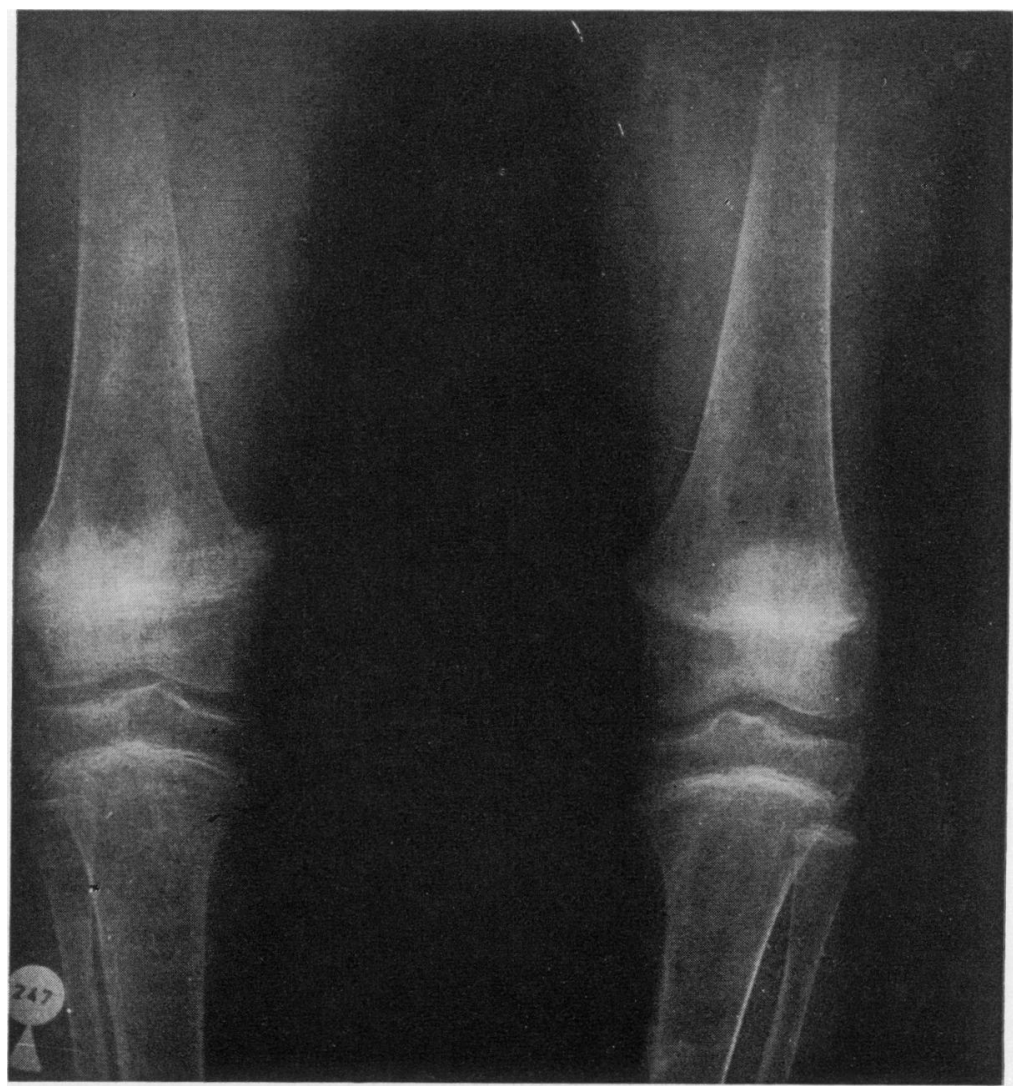

FIG. 6.-Case 2. X-rays of the knees. In the porotic metaphysial areas a fracture is discernible in original films. 
supplement was given to our patients, as their diet was low in calcium. We think that the low calcium intake was an unlikely cause of osteoporosis, though we cannot exclude it, and it could have been an additional causative factor. Case 1 improved in muscular activity, and his calcium balance became positive before his dietary calcium increased (Fig. 2). On the other hand, in Case 2 calcium supplement had no effect on the calcium balance for a long time. The clinical improvement of Case 1 was rapid, and was probably helped by physiotherapy. Her calcium balance became positive within eight weeks, though the $x$-rays showed no improvement at that time.

The basic cause of osteoporosis is obscure. Nordin (1961) suggested it was due to low calcium diet over a prolonged period, but others (Dent and Friedman, 1965; Cloutier et al., 1967; Dent, 1969) did not accept this hypothesis. Dent and Friedman (1965) and Dent (1969) found that in juvenile osteoporosis faecal calcium was almost equal to the dietary intake and was in some cases greater. They suggested that juvenile osteoporosis might result from a combination of two defects: (1) malabsorption of calcium from the bowel, and/or (2) a bone defect preventing incorporation of calcium into the bone.

In our two children the faecal calcium was almost equal to the dietary calcium in one, and was much larger in the other. Our findings thus support Dent's hypothesis of calcium malabsorption.

Our two cases showed metabolic differences. In Case 1 the negative calcium balance was minimal; urinary calcium excretion was normal; phosphorus and magnesium balance were positive. In Case 2 there was a marked negative calcium balance, and urinary calcium excretion was much above normal. In Case 2 phosphorus balance was also negative (until May 1969) with a marked defect in intestinal phosphorus absorption, and a marked urinary phosphorus excretion which was not reduced after the administration of vitamin D. Negative phosphorus balance persisted even when calcium balance was positive and when he was showing clinical improvement. Cloutier et al. (1967) found that their patient with juvenile osteoporosis was in approximate phosphorus balance at the time of spontaneous clinical remission and radiological improvement. Our severely affected patient (Case 2) had both a defect of calcium and of phosphorus absorption. The constancy of the positive magnesium balance of Case 1 and also of the last three magnesium balances of Case 2 suggest that magnesium balance was independent of calcium balance.

Dent and co-workers recommended sex hormones for the treatment of the disease, though they think spontaneous remission always occurs sooner or later (Dent and Friedman, 1965; Dent and Watson, 1966; Cloutier et al., 1967; Dent, 1969). No special treatment was administered to our patients apart from physiotherapy, and calcium with vitamin D supplement.

The authors are grateful to Professor S. A. Doxiadis for permission to publish Case 1 and to Professor C. E. Dent for comments.

\section{REFERENCES}

Cloutier, M. D. Hayles, A. B.. Riggs, B. L., Jowsey, J., and Bickel, W. H. (1967). Juvenile osteoporosis : report of a case including a description of some metabolic and microradiographic studies. Pediatrics, 40, 649.

Dent, C. E. (1968). Osteoporosis. In Ageing of Connective and Skeletal Tissue: Thule International Symposia, 1-3 October 1968, p. 261. Ed. by A. Engel and T. Larsson. Nordiska Bokhandelns Förlag, Stockholm.

Dent, C. E. (1969). Idiopathic juvenile osteoporosis. Archives of Disease in Childhood, 44, 647.

Dent, C. E., and Friedman, M. (1965). Idiopathic juvenile osteoporosis. Quarterly Fournal of Medicine, 34, 177.

Dent, C. E., and Watson, L. (1966). Osteoporosis. Postgraduate Medical fournal, 581.

Fanconi, A., Illig, R., Poley: J. R., Prader, A., Francillon, M., Labhart, A., and Uehlinger, E. (1966). Idiopathische transitorische Osteoporose in Pubertătsalter. Helvetica Paediatrica Acta, 21, 531.

Fiske, C. H., and Subbarow, Y. (1925). The colorimetric determination of phosphorus. Fournal of Biological Chemistry, $66,375$.

King, E. J., and Armstrong, A. R. (1934). A convenient method for determining serum and bile phosphatase activity. Canadian Medical Association fournal, 31, 376.

MacIntyre, I. (1961) High temperature flame photometry. Quoted (from Advances in Clinical Chemistry, 4, 1) by Wootton, I. D. P. (1964). Micro-analysis in Medical Biochemistry, 4th ed., p. 74. Churchill, London.

Nordin, B. E. C. (1961). The pathogenesis of osteoporosis. Lancet, 1,1011 .

Sky-Peck, H. H. (1964). A method for determination of magnesium in serum and urine. Clinical Chemistry, 10, 391.

Whitby, L. G., and Lang, D. (1960). Use of chromium sesquioxide. Quoted (from fournal of Clinical Investigation, 39, 854) by Wootton, I. D. P. (1964). Micro-analysis in Medical Biochemistry, 4th ed., p. 205. Churchill, London. 